\title{
Better outbreak research response needed
}

$\mathrm{T}$ he Canadian Institutes of Health Research's (CIHR) recent announcement of the winners of its \$2.5-million Innovative Ebola Research Grants competition was the culmination of work undertaken since the 2003 SARS crisis to advance Canadian research on outbreaks. But Ebola made it patently obvious that there's at least one lesson from SARS that Canada did not learn: scientists need to respond quickly.

"The Ebola crisis is showing that we still have to refine our strategy to be able to move forward very rapidly," says Dr. Marc Ouellette, who heads CIHR's Institute on Infection and Immunity. He adds that the government's efforts showed that departments could work together in a crisis, but CIHR needs an "embedded" mechanism to respond to future outbreaks.

Bhagirath Singh, Ouellette's predecessor at CIHR, who famously scrambled to find funds for research on SARS and then pushed the government for funding to study H1N1 in 2009, says the problem is that CIHR does not prioritize emerging infectious disease. "We will respond when something really big comes along, we will respond to the news media, rather than ... preparing on a regular basis," says Singh, who now works at the University of Western Ontario.

CIHR's response to the Ebola outbreak in West Africa began in the fall of 2014, after other countries had already allocated millions for research. Ouellette learned that he could tap into Treasury Board funds for emergency use and got CIHR's unanimous support to put the funds toward Ebola. The VSV Ebola vaccine, developed under the auspices of the Public Health Agency of Canada (PHAC), had already emerged as a star initiative. Within a month, CIHR had funded a phase 1 trial of the vaccine in Halifax - a speed Ouellette called "exceptional." The results were used in dose selection for further studies of the vaccine.

Gary Kobinger and other PHAC scientists also moved quickly on an experimental cocktail of monoclonal antibiodies, ZMapp, testing it with an international team and publishing successful results in monkeys by late

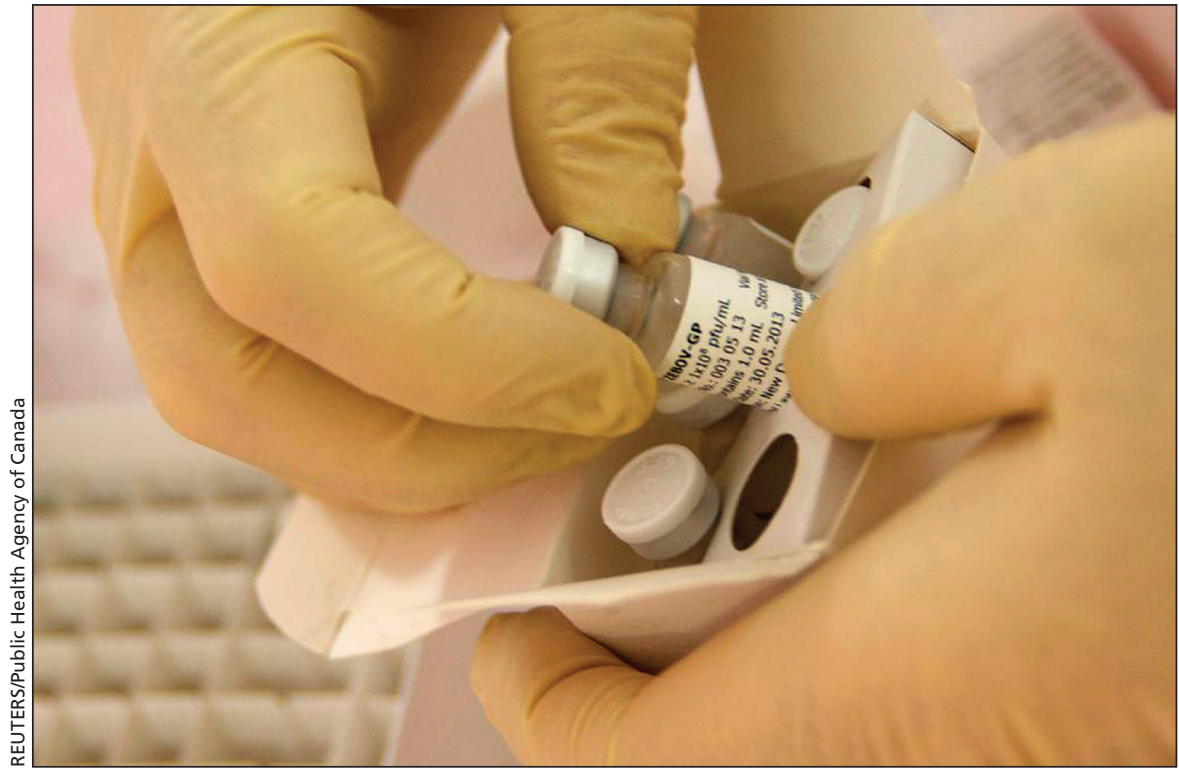

Scientists at the National Microbiology Lab in Winnipeg, Manitoba, prepare an experimental Ebola vaccine for shipment to the World Health Organization (WHO) in Geneva in October 2014

August. PHAC invested $\$ 23.5$ million to further its Ebola drug research in November.

Unfortunately, that rapid pace was not replicated in other Ebola research endeavours.

Dr. Dominique Charron, a scientist leading programs for the federal government's International Development Research Centre (IDRC), contacted Ouellette in August asking if there was something more they could do. The two worked with PHAC and the Department of Foreign Affairs, Trade and Development (DFATD) on an agreement to jointly contribute to a phase 3 trial of the VSV vaccine that the World Health Organization (WHO) and Norway were organizing in Guinea. But the money was not committed until December.

"Certainly, the mechanism for unlocking significant research funding from the central budget is clunky," says Charron.

Canada's role in the trial was far more limited than the IDRC, CIHR, PHAC and DFATD partnership originally envisioned. In November, CIHR requested proposals "to help develop and conduct a clinical trial led by a team from Guinea," but after launching the call, they discovered that a trial team "was already emerging on the WHO side," Charron says.
With the WHO coordinating the trial, Canada held its scientists' proposals in reserve so despite Canada's expertise on clinical trials, Canadians played only supporting roles: biostatistician Benoît Mâsse of Montréal's Centre de recherché du CHU Sainte-Justine chairs the trial's Data Safety Monitoring Board (DSMB) and Dr. John Spika of PHAC cochairs the trials' Scientific Advisory Group, which also includes Dalhousie medical anthropologist Janice Graham.

"I don't think that this should be trumpeted as evidence of Canadian leadership in the Ebola epidemic," says anthropologist Dr. Vinh-Kim Nguyen of Université de Montréal, who is working in Guinea with funding from the European Union.

In December, CIHR granted $\$ 80000$ to University of Toronto immunologist Eleanor Fish for a pilot study of interferon in Ebola patients in Guinea; she is preparing preliminary results for publication. And now, as the outbreak peters out, 12 of 41 applicants have won "Innovative Ebola" grants, including University of Toronto physician Dr. Adrienne Chan, who will track Ebola survivors in Sierra Leone and describe their lingering medical problems. Miriam Shuchman, Toronto, Ont. 